\title{
Alleviation of cobalt stress by exogenous sodium nitroprusside in iceberg lettuce
}

\author{
Halil Samet $^{1^{*}}$ \\ ${ }^{1}$ Kocaeli University, Vocational School of Food and Agriculture, Arslanbey Campus 41285 Kartepe, Kocaeli, Turkey. \\ *Corresponding author (halilsamet@yahoo.com).
}

Received: 28 August 2019; Accepted: 10 January 2020; doi:10.4067/S0718-58392020000200161

\begin{abstract}
Excessive amounts of heavy metals (HMs) in the rooting media affect adversely plant growth, cause loss of yields, and undesirable effects on crops. The aim of this study was to investigate the effects of exogenous sodium nitroprusside (SNP) $(200 \mu \mathrm{M})$, a nitric oxide (NO) donor, on toxic cobalt (Co) level $(200 \mu \mathrm{M})$ in iceberg lettuce (Lactuca sativa $\mathrm{L}$. var. capitata). Plants were grown in a hydroponic system (modified Hoagland solution and perlite as inert media) inside a greenhouse under natural light conditions (average temperature $27-18^{\circ} \mathrm{C}$ day-night and humidity $63 \%$ ). Results indicated that excessive Co caused significant reductions in fresh (FW) and dry weights (DW) of the shoots and roots, photosynthetic pigment contents of leaves, and metallic cation concentration of shoots and roots. Also, hydrogen peroxide $\left(\mathrm{H}_{2} \mathrm{O}_{2}\right)$, lipid peroxidation, proline accumulation, catalase (CAT) and ascorbate peroxidase (APX) activities, and total Co accumulation rate (TAR) increased significantly with excessive Co. Compared to Co application, Co+SNP application showed a $48.5 \%$ and $31.1 \%$ increase in FW and DWs, respectively. Moreover, chlorophyll (Chl) $a, \mathrm{Chl} b, \mathrm{Chl} a+b$ and carotenoid (Car) content increased $54.5 \%, 64.4 \%, 56.6 \%$, and $39.7 \%$, respectively. Similarly, shoot Co uptake $(69.7 \%)$, shoot and root Fe concentration (21.7\% and $149.4 \%$, respectively), root Zn concentration (6.1\%), and net accumulation of Fe and $\mathrm{Mn}$ via roots (4.5- and 1.6-fold, respectively) were increased. Consequently, the alleviating effect of exogenous NO on Co toxicity in iceberg lettuce could depend on NO-induced increase in antioxidant enzyme activity and its multifunctional role in plant cellular mechanism.
\end{abstract}

Key words: Accumulation, chlorophyll, cobalt, enzymatic activities, growth, Lactuca sativa, nitric oxide.

\section{INTRODUCTION}

Excessive heavy metals (HMs) in the rooting medium adversely affect plant growth, lead to a loss of yield and have undesirable effects on crops ( $\mathrm{Li}$ et al., 2009; Marschner, 2012). Cobalt is classified as a beneficial element for plants (Marschner, 2012), but excessive amounts in plant tissues cause irreversible damage to plant cells and cell membranes, which adversely affects the uptake of water and nutrients and causes a reduction in plant growth (Gopal et al., 2003; Chatterjee and Chatterjee., 2005; Li et al., 2009). In recent studies, the toxicity threshold of Co has been considered to be $50 \mu \mathrm{M}$ and application levels above this value have been reported to delay normal growth and development of test plants and reduce chlorophyll content (Gopal et al., 2003; Karuppanapandian and Kim, 2013; Agnihotri et al., 2014).

In plants exposed to HM toxicity, the balance between reactive oxygen species (ROS) and the defense mechanism of antioxidants is disturbed, resulting in oxidative stress. The first indicators of this stress are an increase in lipid peroxidation and $\mathrm{H}_{2} \mathrm{O}_{2}$ content (Mostofa et al., 2014; Lwalaba et al., 2020). The increase in ROS in the cell triggers the antioxidant capacity of cells and causes an increase in the activity of antioxidative enzymes (CAT, APX, etc.) (Wang et al., 2010; Mostofa et al., 2014). On the other hand, the content of free proline that acts as a metal chelator or antioxidative defense molecule also increases (Hayat et al., 2012). The interaction between resistance to environmental stress and anti-oxidative 
systems in plants has been studied by many researchers (Gopal et al., 2003; Chatterjee and Chatterjee, 2005; Ali et al., 2010; Karuppanapandian and Kim, 2013).

Nitric oxide (NO) is a highly reactive molecule with many biological pathways that have proven to be protective against damage induced by oxidative stress conditions (Mostofa et al., 2014; Bai et al., 2015). Applied sodium nitroprusside (SNP), as NO donor, at low concentrations was found to be effective in regulating abiotic stress conditions, including the toxicity of HMs. For instance, it has been reported to alleviate Cd toxicity in rice leaves (Panda et al., 2011) and ryegrass seedling (Bai et al., 2015) and $\mathrm{Cu}$ toxicity in tomato plants (Wang et al., 2010).

Published literature has demonstrated the importance of exogenous NO to protect plants against the toxicity of HMs. In particular, reports related to the role of $\mathrm{NO}$ in Co toxicity are still limited and further studies are needed to explain interactions. The aim of this study was therefore to investigate the effects of exogenous SNP on the regulation of Co toxicity in iceberg lettuce, a leafy vegetable consumed commonly all over the world.

\section{MATERIALS AND METHODS}

Seedlings of iceberg lettuce (Lactuca sativa L. var. capitata) 'Saula' were transferred to the polyethylene containers of $2 \mathrm{~L}$ capacity (one plant each) at a hydroponic system (modified Hoagland solution and perlite as inert media) inside a greenhouse in natural light conditions. The climatic conditions in the greenhouse during the experiment were average air temperature $27-18^{\circ} \mathrm{C}$ (day-night) and average relative humidity $63 \%$.

Before Co and sodium nitroprusside (SNP) application, lettuce seedlings were watered with different rates of modified Hoagland solution for $11 \mathrm{~d}$ ( $5 \mathrm{~d}$ quarter-strength; $3 \mathrm{~d}$ half-strength; $3 \mathrm{~d}$ full-strength) for acclimatization. This solution contains $5 \mathrm{mM}$ calcium nitrate tetrahydrate $\left[\mathrm{Ca}\left(\mathrm{NO}_{3}\right)_{2} \cdot 4 \mathrm{H}_{2} \mathrm{O}\right], 5 \mathrm{mM}$ potassium nitrate $\left(\mathrm{KNO}_{3}\right), 2 \mathrm{mM}$ magnesium sulfate heptahydrate $\left(\mathrm{MgSO}_{4} \cdot 7 \mathrm{H}_{2} \mathrm{O}\right), 1 \mathrm{mM}$ potassium di-hydrogen phosphate $\left(\mathrm{KH}_{2} \mathrm{PO}_{4}\right), 45.5 \mu \mathrm{M}$ boric acid $\left(\mathrm{H}_{3} \mathrm{BO}_{3}\right), 44.7$ $\mu \mathrm{M}$ iron sulfate heptahydrate $\left(\mathrm{FeSO}_{4} \cdot 7 \mathrm{H}_{2} \mathrm{O}\right), 30.0 \mu \mathrm{M}$ sodium chloride $(\mathrm{NaCl}), 9.1 \mu \mathrm{M}$ manganese sulfate monohydrate $\left(\mathrm{MnSO}_{4} \cdot \mathrm{H}_{2} \mathrm{O}\right), 0.77 \mu \mathrm{M}$ zinc sulfate heptahydrate $\left(\mathrm{ZnSO}_{4} \cdot 7 \mathrm{H}_{2} \mathrm{O}\right), 0.32 \mu \mathrm{M}$ copper sulfate pentahydrate $\left(\mathrm{CuSO}_{4} \cdot 5 \mathrm{H}_{2} \mathrm{O}\right), 0.10$ $\mu \mathrm{M}$ ammonium molybdate tetrahydrate $\left[\left(\mathrm{NH}_{4}\right)_{2} \mathrm{Mo}_{7} \mathrm{O}_{24} \cdot 4 \mathrm{H}_{2} \mathrm{O}\right]$, and $54.8 \mu \mathrm{M}$ disodium EDTA dihydrate $\left(\mathrm{Na}_{2} \mathrm{EDTA} \cdot 2 \mathrm{H}_{2} \mathrm{O}\right)$. During the experimental period, the $\mathrm{pH}$ of the medium was adjusted to 6.5 .

Four-week-old lettuce seedlings were produced in a mixture of vermiculite and perlite $(2 / 1 \mathrm{v} / \mathrm{v})$ and were obtained from the seedling market when reached the 5 to 6 leaves-stage were exposed to four applications, including control, 200 $\mu \mathrm{M}$ Co (from $\mathrm{CoSO}_{4} \cdot 7 \mathrm{H}_{2} \mathrm{O}$ ), $200 \mu \mathrm{M} \mathrm{SNP}\left[\mathrm{Na}_{2}\left(\mathrm{Fe}(\mathrm{CN})_{5} \mathrm{NO}\right) \cdot 2 \mathrm{H}_{2} \mathrm{O}\right]$ (Sigma Aldrich, St. Louis, Missouri, USA), and $200 \mu \mathrm{M}$ SNP and $200 \mu \mathrm{M}$ Co as dissolved in full-strength modified Hoagland solution. The Co concentrations were selected based on previous studies and taking into consideration the differentiated toxicity for diverse plant species. The experiment was laid out as a completely randomized factorial design with three replicates for each treatment.

\section{Sampling and harvest of plants}

After $21 \mathrm{~d}$ lettuce plants were harvested and separated into shoots and roots for determining the fresh and dry weight of biomass. The shoots and roots were washed with running tap water and three-times rinsed with de-ionized water to remove any particles attached to the plant surfaces. Then all samples were dried in an air forced oven at $70{ }^{\circ} \mathrm{C}$ until a constant mass was reached. After cooling down till room temperature they were weighted for the shoot and root dry weights and subsequently ground to powder for nutrient ion analysis.

\section{Determination of photosynthetic pigments, enzyme extraction and assay}

Photosynthetic pigments were measured in the youngest fully expanded fresh leaves before harvest. The fresh leaf samples $(0.25 \mathrm{~g})$ were cut into small pieces and were extracted in $10 \mathrm{~mL}$ acetone $(90 \%, \mathrm{v} / \mathrm{v})$ with a homogenizer (Heidolph DIAX 900, Kelheim, Germany). The extract was then filtered and the absorbance of the extract was measured at 663, 645, and $470 \mathrm{~nm}$ using a spectrophotometer (UV-1201, Shimadzu, Kyoto, Japan). The chlorophyll (Chl $a, \mathrm{Chl} b$ ), and carotenoid (Car) contents were calculated according to the formula reported by Lichtenthaler (1987).

For extraction and assay of enzymes, fully matured leaves $(1.0 \mathrm{~g})$ were homogenized by using homogenizer with $5 \mathrm{~mL}$ extraction buffer (100 mM Na-phosphate buffer, pH 7.5) containing $0.5 \mathrm{mM}$ EDTA-Na ${ }_{2}$ at $4{ }^{\circ} \mathrm{C}$. Also, $1 \mathrm{mM}$ ascorbate was included in extraction buffer for ascorbate peroxidase due to the instability of ascorbate peroxidase (APX) in the 
absence of ascorbate (Shigeoka et al., 2002). The homogenate was centrifuged at $10000 \mathrm{~g}$ for $5 \mathrm{~min}$. The supernatant was used for determining enzyme activity and a spectrophotometer was used for all colorimetric measurements (including enzyme activities) at $25^{\circ} \mathrm{C}$.

The activity of catalase (CAT) (EC 1.11.1.6) was determined by using a reaction solution $(2.5 \mathrm{~mL}$ per $0.2 \mathrm{~mL}$ supernatant, $\mathrm{pH}$ 7) containing $50 \mathrm{mM} \mathrm{KH}_{2} \mathrm{PO}_{4}$ and $1.5 \mathrm{mM} \mathrm{H}_{2} \mathrm{O}_{2}$ as a decrease in absorbance at $240 \mathrm{~nm}$ for $1 \mathrm{~min}$ following the decomposition of $\mathrm{H}_{2} \mathrm{O}_{2}$ (Chance and Maehly, 1955) and calculated using the extinction coefficient $\left(\varepsilon=40 \mathrm{mM} \mathrm{cm}^{-1}\right)$ for $\mathrm{H}_{2} \mathrm{O}_{2}$. The activity of APX (EC 1.11.1.11) was determined by using a reaction solution $(3.0 \mathrm{~mL}$ per $0.1 \mathrm{~mL}$ supernatant, $\mathrm{pH}$ 7) containing $50 \mathrm{mM} \mathrm{KH}_{2} \mathrm{PO}_{4}, 0.05 \mathrm{mM}$ ascorbic acid, $0.1 \mathrm{mM}$ EDTA-Na 2 , and $1.5 \mathrm{mM} \mathrm{H}_{2} \mathrm{O}_{2}$ as a decrease of ascorbate and measuring the change in absorbance at $290 \mathrm{~nm}$ for 1 min (Nakano and Asada, 1981) and calculated using the extinction coefficient $\left(\varepsilon=2.8 \mathrm{mM} \mathrm{cm}^{-1}\right)$ for ascorbate.

Determination of membrane damage and hydrogen peroxide $\left(\mathrm{H}_{2} \mathrm{O}_{2}\right)$, lipid peroxidation, and proline accumulation Membrane permeability (MP) (EC \%) for shoot disc samples was measured by the electrical conductivity (EC) method as described by Yan et al. (1996).

The $\mathrm{H}_{2} \mathrm{O}_{2}$ content of the leaves was extracted and estimated as described by Mukherjee and Choudhuri (1983). Leaf samples $(0.25 \mathrm{~g})$ were homogenized by a homogenizer in $5 \mathrm{~mL}$ with cold acetone and filtered. An aliquot $(1 \mathrm{~mL})$ of the extracted solution was mixed with $4 \mathrm{~mL}$ titanium dioxide $\left(\mathrm{TiO}_{2}\right)$ reaction solution in $\mathrm{TiO}_{2}(0.06 \%, \mathrm{w} / \mathrm{v}), \mathrm{K}_{2} \mathrm{SO}_{4}(0.6 \%$, $\mathrm{w} / \mathrm{v})$, and $\mathrm{H}_{2} \mathrm{SO}_{4}(10 \%, \mathrm{v} / \mathrm{v})$ and added $5 \mathrm{~mL}$ concentrated ammonia $\left(\mathrm{NH}_{3}\right)$ solution. The mixture was centrifuged at 10000 $\mathrm{g}$ for $5 \mathrm{~min}$. The intensity of the yellow color of the supernatant was measured at $415 \mathrm{~nm}$. The $\mathrm{H}_{2} \mathrm{O}_{2}$ content was calculated from a standard curve plotted with the range of 100-1000 $\mathrm{nmol} \mathrm{H}_{2} \mathrm{O}_{2}$.

Lipid peroxidation of leaves is a good indicator for assessing membrane damage and was estimated by the content of malondialdehyde (MDA), the end product of lipid peroxidation, described by Hodges et al. (1999). In brief, mature leaf samples $(0.25 \mathrm{~g})$ were homogenized by using homogenizer in $5 \mathrm{~mL} 0.1 \%$ trichloroacetic acid (TCA) and the homogenate was centrifuged at $5000 \mathrm{~g}$ for $5 \mathrm{~min}$. After that, $4 \mathrm{~mL}$ of $20 \%$ TCA containing $0.5 \%$ thiobarbituric acid (TBA) were added to $1 \mathrm{~mL}$ aliquot of the supernatant. The mixture was heated in a boiling water bath $\left(95^{\circ} \mathrm{C}\right)$ for $15 \mathrm{~min}$ and allowed to $\mathrm{cool}$ in an ice bath quickly. The supernatant was centrifuged at $10000 \mathrm{~g}$ for $5 \mathrm{~min}$ and the resulting supernatant was used for spectrophotometric determination of MDA. The absorbance at $532 \mathrm{~nm}$ was recorded and corrected for nonspecific absorbance at $600 \mathrm{~nm}$. The MDA content was calculated by means of an extinction coefficient of $\left(\varepsilon=155 \mathrm{mM} \mathrm{cm}^{-1}\right)$.

Free proline was extracted from $0.25 \mathrm{~g}$ fresh leaf samples homogenized with $5 \mathrm{~mL} 3 \%(w / v)$ sulfosalicylic acid at $4{ }^{\circ} \mathrm{C}$ and estimated by ninhydrin reagent (Bates et al., 1973).

\section{Determination of metal ions, and uptake of Co and Fe accumulation}

For the measurement of nutrient ion concentrations, $500 \mathrm{mg}$ each of the shoot samples was dry-ashed in a muffle furnace at $500{ }^{\circ} \mathrm{C}$ for $6 \mathrm{~h}$ and then the cooled ash was dissolved in $5 \mathrm{~mL}, 0.1 \mathrm{M}$ hydrochloric acid (HCl) solution (Miller, 1998). The concentrations of $\mathrm{Co}$ and the other metal ions $\left(\mathrm{Fe}^{2+}, \mathrm{Zn}^{2+}, \mathrm{Mn}^{2+}\right.$, and $\left.\mathrm{Cu}^{2+}\right)$ were measured by using inductively coupled plasma optical emission spectrometry (ICP-OES) (Perkin Elmer Optima 2100 DV; Waltham, Massachusetts, USA).

The Co uptake, total accumulation rate (TAR) of Co, and net accumulation of ion via roots were calculated by Equations 1, 2, and 3 (Moradi and Ehsanzadeh, 2015; Cikili et al., 2016):

$$
\begin{gathered}
\text { Ion uptake }\left(\mu \mathrm{g} \text { plant }^{-1}\right)=[D W]_{\text {shoot or root }} \times[\text { ion }]_{\text {shoot or root }} \\
\text { TAR of Co }\left(\mu \mathrm{g} \mathrm{g}^{-1} \mathrm{DWd} d^{-1}\right)=\left(\text { ion }_{\text {shoot }} \times D W_{\text {shoot }}\right)+\left(\text { ion }_{\text {root }} \times D W_{\text {root }}\right) / \text { growth day } \times\left(D W_{\text {shoot }}+D W_{\text {root }}\right) \\
\text { Net Acc }\left(\mu g g^{-1} D W\right)=[\text { ion }]_{\text {shoot }} / D W_{\text {root }}
\end{gathered}
$$

where $[\text { ion }]_{\text {shoot or root }}$ is ion concentration in shoot or root.

\section{Statistical analysis}

Statistical analysis of the experimental data was analyzed using ANOVA with the MINITAB package program (Minitab Corp., State College, Pennsylvania, USA). Multiple comparisons of means among applications (i.e. control, SNP, and Co levels) were analyzed using Duncan's multiple range test at the significance level $(\alpha 0.05)$. 


\section{RESULTS}

Plant growth and photosynthetic pigment content

Applied Co caused a significant reduction in both shoot and root FW and DW in iceberg lettuce compared to control, whereas applied SNP showed a close effect to control (Figure 1). In comparison with Co applied plants, the application of Co+SNP caused a considerable increase in FW (48.5\%) and in DW (31.1\%) in the shoot, but any ameliorative effect was not observed in the root of plants exposed to Co.

Applied Co caused a significant decrease in the photosynthetic pigment contents (Chl $a$, Chl $b, \mathrm{Chl} a+b$, and Car) of the test plants (Table 1). These decreases were by $51.5 \%, 72.9 \%, 57.2 \%$, and $48.0 \%$, respectively. However, Co+SNP increased significantly $\mathrm{Chl} a(54.5 \%)$, Chl $a+b$ (64.4\%), and Car (56.6\%) content compared to Co-toxic plants.

\section{Membrane permeability, hydrogen peroxide, lipid peroxidation, and proline accumulation}

The effect of toxic Co levels on the leaves of iceberg lettuce on MP, the contents of $\mathrm{H}_{2} \mathrm{O}_{2}$ and MDA, and proline accumulation is given in Table 2. The Co application led to a significant increase in the MDA content by $24.5 \%$, this increase was 2.3-fold in the $\mathrm{H}_{2} \mathrm{O}_{2}$ content and 3.8-fold in proline accumulation compared to Co-toxic plants. The SNP application caused a decrease only in the MDA content by $28.9 \%$. Moreover, in comparison with Co-toxic plants, the Co+SNP application led to a notable reduction in the content of $\mathrm{H}_{2} \mathrm{O}_{2}$ and MDA and proline accumulation by $48.0 \%$, $37.7 \%$, and $50.0 \%$, respectively (Table 2 ).

Figure 1. Effects of Co and sodium nitroprusside (SNP) on iceberg lettuce fresh weight (A) and dry weight (B).
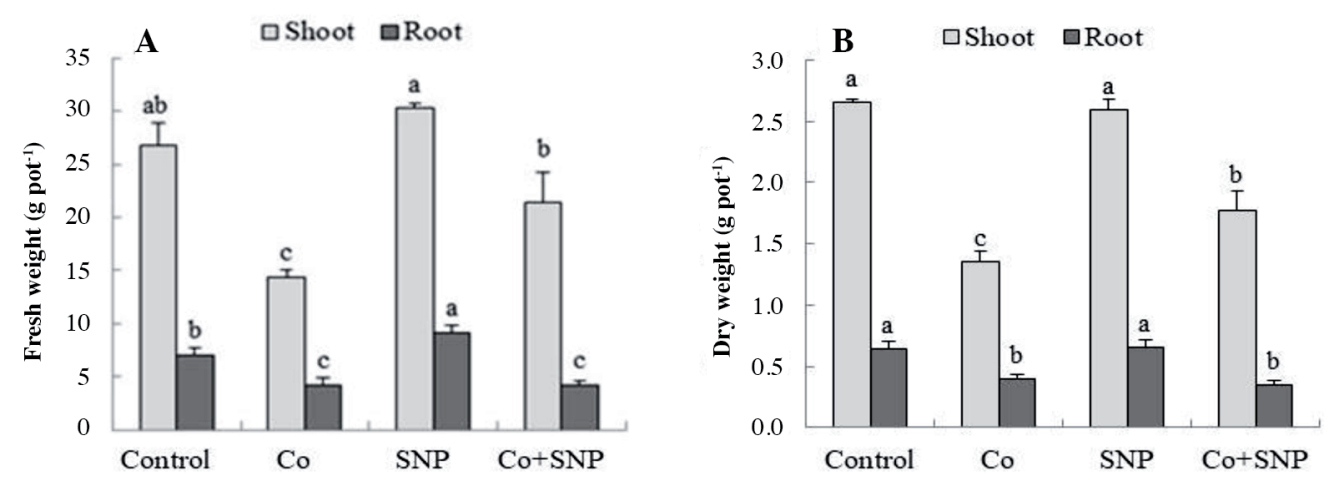

Each value refers to the average of three replicates and error bars represent the standard error (SE). Different letters on the bars indicate significant differences according to Duncan's multiple range test $(p<0.05)$.

Table 1. Effects of Co and sodium nitroprusside (SNP) on photosynthetic pigments in iceberg lettuce leaves.

\begin{tabular}{lccccc}
\hline & \multicolumn{5}{c}{ Photosynthetic pigments } \\
\cline { 2 - 6 } Applications & Chl $a$ & Chl $b$ & Chl a $b$ & Car & Car/Chl \\
\cline { 2 - 6 } & \multicolumn{5}{c}{$\mathrm{mg} \mathrm{g}^{-1} \mathrm{FW}$} \\
Control & $0.617 \pm 0.030 \mathrm{a}$ & $0.218 \pm 0.031 \mathrm{a}$ & $0.835 \pm 0.037 \mathrm{a}$ & $0.450 \pm 0.016 \mathrm{a}$ & $0.540 \pm 0.007 \mathrm{~b}$ \\
Co & $0.299 \pm 0.083 \mathrm{c}$ & $0.059 \pm 0.026 \mathrm{c}$ & $0.357 \pm 0.108 \mathrm{c}$ & $0.234 \pm 0.053 \mathrm{c}$ & $0.685 \pm 0.047 \mathrm{a}$ \\
SNP & $0.597 \pm 0.017 \mathrm{ab}$ & $0.161 \pm 0.011 \mathrm{ab}$ & $0.758 \pm 0.008 \mathrm{a}$ & $0.420 \pm 0.004 \mathrm{ab}$ & $0.554 \pm 0.003 \mathrm{~b}$ \\
Co + SNP & $0.462 \pm 0.024 \mathrm{~b}$ & $0.097 \pm 0.009 \mathrm{bc}$ & $0.559 \pm 0.034 \mathrm{~b}$ & $0.327 \pm 0.019 \mathrm{~b}$ & $0.584 \pm 0.001 \mathrm{~b}$ \\
$F$-Test & $* *$ & $* *$ & $* *$ & $* *$ & $*$ \\
\hline
\end{tabular}

Chl: Chlorophyll; Car: Carotenoid.

Each value refers to the average of three replicates and shows the standard error (SE). Different letters in the same column indicate significant differences according to Duncan's multiple range test $(p<0.05)$. 
Table 2. Effects of Co and sodium nitroprusside (SNP) on membrane permeability, hydrogen peroxide content, lipid peroxidation, and proline accumulation in iceberg lettuce.

\begin{tabular}{lccrc}
\hline Applications & Membrane permeability & $\mathrm{H}_{2} \mathrm{O}_{2}$ content & MDA content & Proline \\
\cline { 3 - 4 } & $\mathrm{EC}, \%$ & & $\mu \mathrm{g} \mathrm{g}^{-1} \mathrm{FW}$ & \\
Control & $11.42 \pm 0.65$ & $3.89 \pm 0.02 \mathrm{~b}$ & $12.58 \pm 0.57 \mathrm{~b}$ & $0.12 \pm 0.01 \mathrm{c}$ \\
Co & $13.67 \pm 0.55$ & $8.84 \pm 0.43 \mathrm{a}$ & $15.66 \pm 0.16 \mathrm{a}$ & $0.46 \pm 0.05 \mathrm{a}$ \\
$\mathrm{SNP}$ & $10.23 \pm 1.12$ & $4.52 \pm 0.47 \mathrm{~b}$ & $8.94 \pm 0.19 \mathrm{c}$ & $0.13 \pm 0.01 \mathrm{c}$ \\
Co + SNP & $12.53 \pm 1.99$ & $4.60 \pm 0.60 \mathrm{~b}$ & $9.75 \pm 0.43 \mathrm{c}$ & $0.23 \pm 0.03 \mathrm{~b}$ \\
$F$-Test & $\mathrm{ns}$ & $* * *$ & $* * *$ & $* * *$ \\
\hline
\end{tabular}

MDA: Malondialdehyde; EC: electrical conductivity.

Each value refers to the average of three replicates and shows the standard error (SE). Different letters in the same column indicate significant differences according to Duncan's multiple range test $(p<0.05)$.

\section{Enzymatic activities and Co accumulation}

The variation in the activities of CAT and APX enzymes of the test plant is presented in Figure 2. Excessive Co caused a significant increase in both CAT and APX by more than 8 -fold and 25-fold, respectively. But, these activities were considerably lowered by the Co+SNP application.

Applied Co and SNP to the rooting media caused a notable increase in shoot and root Co concentration and Co uptake. But the effects of $\mathrm{Co}+\mathrm{SNP}$ application on Co concentrations and uptake showed differences in shoots and roots. This application (Co+SNP) caused a $28.5 \%$ increase in shoot Co concentrations, while a $21.9 \%$ decrease in root Co concentrations (Table 3). Also, Co and Co+SNP applications caused a notable increase in the TAR of Co by 46.7- and 49.1-fold more than the control, respectively. The effects of SNP on the concentration, uptake, and accumulation of Co was not considerable. On the other hand, Co accumulated more in root than in shoot in all applications.

\section{$\mathrm{Fe}, \mathrm{Zn}, \mathrm{Mn}$, and $\mathrm{Cu}$ concentrations}

The changes in metallic cation concentrations $(\mathrm{Fe}, \mathrm{Zn}, \mathrm{Mn}$, and $\mathrm{Cu}$ ) in shoot and roots are collectively given in Figure 3. Applied Co did not affect considerably the Fe concentrations in shoot and root. But, applied SNP caused a significant increase in Fe concentration in the shoot and root by $43.5 \%$ and $93.1 \%$, respectively, compared to control. Similar increases with the Co+SNP were observed in Fe concentrations in the shoot by $21.7 \%$ and in the root by $149.4 \%$ (Figure 3A). Besides, applied Co decreased remarkably Zn concentrations in both shoot and root by $30.0 \%$ and $29.6 \%$, respectively. But, the Co+SNP application caused a notable amelioration only in the root $\mathrm{Zn}$ concentration by $6.1 \%$ compared to Co toxic plants (Figure 3B). On the other hand, applied Co caused a significant increase in Mn concentration in the shoot by $17.3 \%$, but nonsignificant increase in root was observed. The SNP application caused a notable increase in this parameter in shoot and root at the rate of $69.0 \%$ and $89.9 \%$, respectively (Figure 3C). Also, in comparison with control, both Co and $\mathrm{Co}+\mathrm{SNP}$ applications decreased the $\mathrm{Cu}$ concentration in the shoot by $32.1 \%$ and $46.8 \%$, respectively (Figure 3D).

Figure 2. Effects of Co and sodium nitroprusside (SNP) on enzymatic activities in iceberg lettuce.
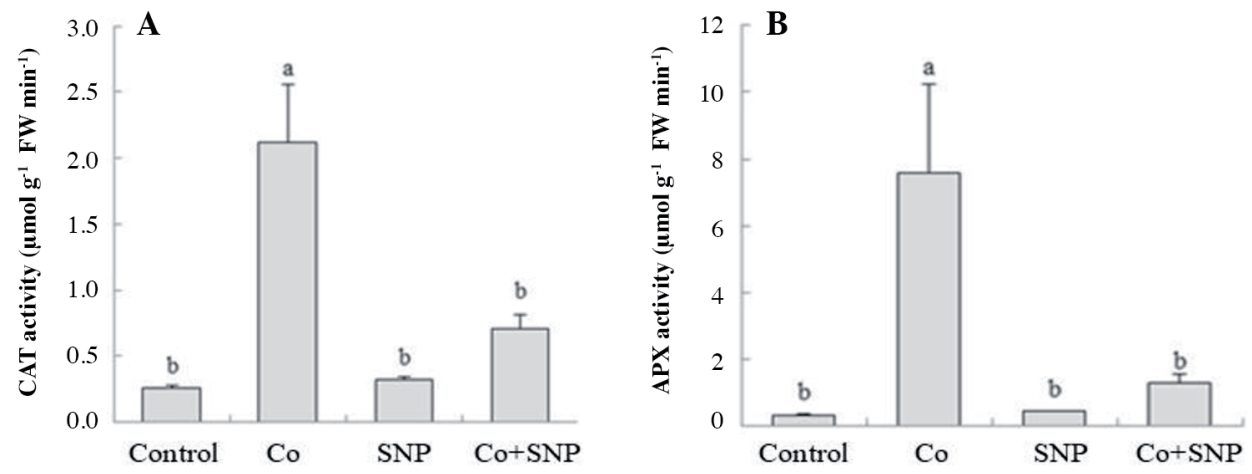

CAT: Catalase; APX: ascorbate peroxidase.

Each value refers to the average of three replicates and error bars represent the standard error (SE). Different letters on the bars indicate significant differences according to Duncan's multiple range test $(p<0.05)$. 
Table 3. Effects of Co and sodium nitroprusside (SNP) on the concentration, uptake, total accumulation rate (TAR) of Co in iceberg lettuce.

\begin{tabular}{|c|c|c|c|c|c|}
\hline \multirow[b]{2}{*}{ Applications } & \multicolumn{2}{|c|}{ Co concentration } & \multicolumn{2}{|c|}{ Co uptake } & \multirow[b]{2}{*}{ TAR of Co } \\
\hline & Shoot & Root & Shoot & Root & \\
\hline & $\longrightarrow \mu \mathrm{g}$ & DW & $\longrightarrow \mu$ & $\mathrm{nt}^{-1}$ & $\mu \mathrm{g} \mathrm{g}^{-1} \mathrm{DW} \mathrm{d} \mathrm{d}^{-1}$ \\
\hline Control & $0.18 \pm 0.01 \mathrm{c}$ & $6.88 \pm 0.26 c$ & $0.46 \pm 0.04 \mathrm{c}$ & $4.35 \pm 0.40 \mathrm{c}$ & $0.8 \pm 0.08 b$ \\
\hline Co & $58.08 \pm 5.50 b$ & $873.07 \pm 56.10 \mathrm{a}$ & $77.68 \pm 4.91 b$ & $345.40 \pm 34.5 \mathrm{a}$ & $35.5 \pm 4.99 \mathrm{a}$ \\
\hline SNP & $3.72 \pm 0.18 c$ & $33.94 \pm 1.20 \mathrm{c}$ & $9.62 \pm 0.66 c$ & $22.46 \pm 2.08 c$ & $5.0 \pm 0.65 b$ \\
\hline $\mathrm{Co}+\mathrm{SNP}$ & $74.65 \pm 4.68 \mathrm{a}$ & $681.80 \pm 47.60 \mathrm{~b}$ & $131.83 \pm 14.4 \mathrm{a}$ & $237.69 \pm 17.5 b$ & $37.3 \pm 1.93 \mathrm{a}$ \\
\hline$F$-Test & *** $*$ & $* * *$ & $* * *$ & $* * *$ & $* * *$ \\
\hline
\end{tabular}

Each value refers to the average of three replicates and shows the standard error (SE). Different letters in the same column indicate significant differences according to Duncan's multiple range test $(p<0.05)$.

Figure 3. Effects of Co and sodium nitroprusside (SNP) on microelement concentrations in the shoot and root of iceberg lettuce.
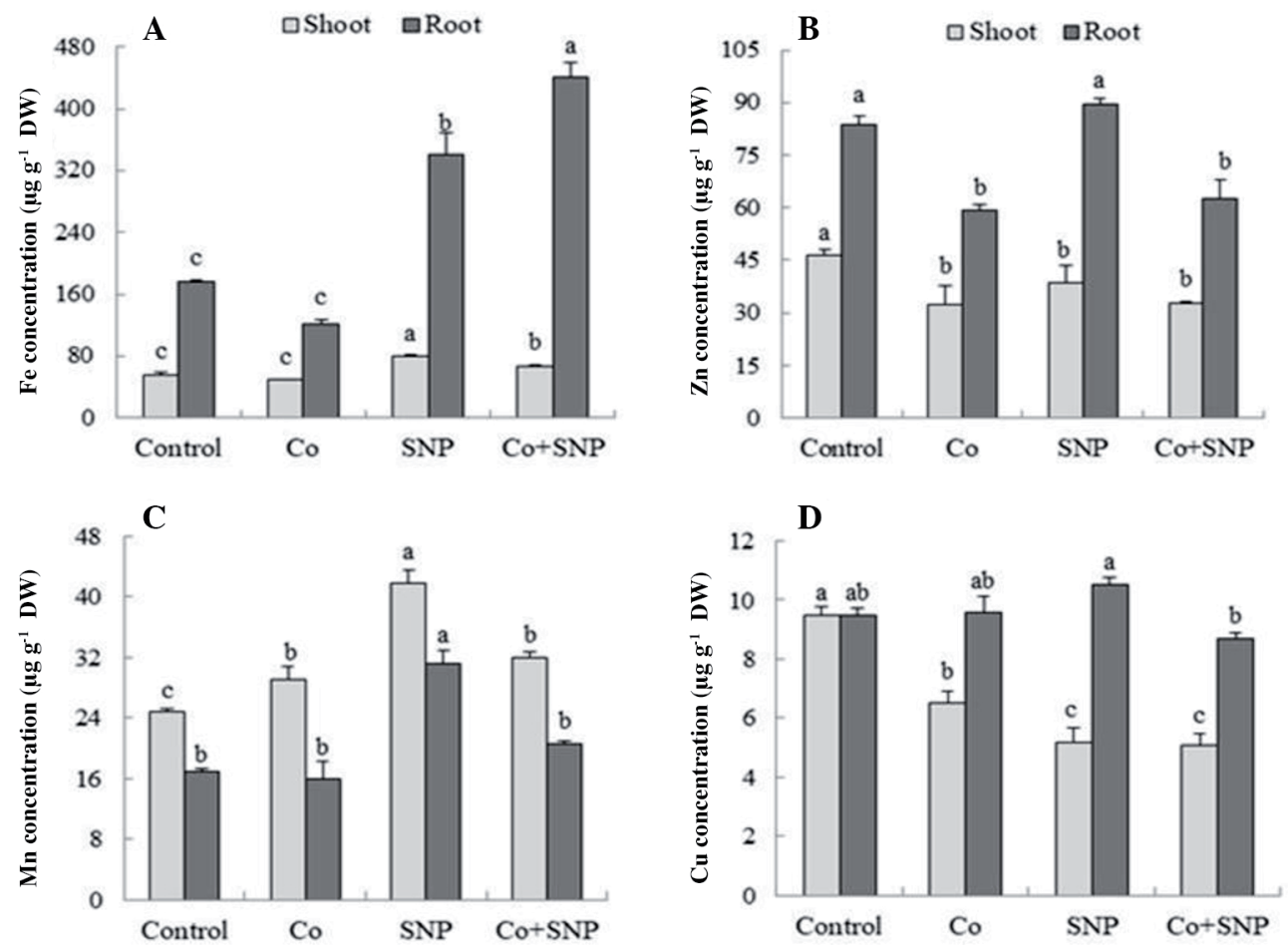

Each value refers to the average of three replicates and error bars represent the standard error (SE). Different letters on the bars indicate significant differences according to Duncan's multiple range test $(p<0.05)$.

\section{Net accumulation of ions via roots}

Net accumulation of metallic cations ( $\mathrm{Co}, \mathrm{Fe}, \mathrm{Zn}, \mathrm{Mn}$, and $\mathrm{Cu}$ ) by the way of a unit root are summarized in Table 4 . Compared to control, the net accumulation of Co increased significantly with Co application by 140 -fold, but this parameter of $\mathrm{Cu}$ decreased by $36.5 \%$. Moreover, net accumulation values of $\mathrm{Fe}, \mathrm{Zn}$, and $\mathrm{Mn}$ were found nonsignificant. While SNP applied alone caused a notable increase in a net accumulation of $\mathrm{Mn}$ by $61.2 \%$, a decrease in a net accumulation of $\mathrm{Cu}$ by $37.4 \%$. On the other hand, the Co+SNP application increased significantly the net accumulation of both Fe (4.5-fold) and $\mathrm{Mn}(28.6 \%)$. 
Table 4. Effects of Co and sodium nitroprusside (SNP) on net accumulation of metallic cations in iceberg lettuce.

\begin{tabular}{lccccc}
\hline & \multicolumn{5}{c}{ Net accumulation of metallic cations via roots } \\
\cline { 2 - 6 } Applications & $\mathrm{Co}$ & $\mathrm{Fe}$ & $\mathrm{Zn}$ & $\mathrm{Mn}$ & $\mathrm{Cu}$ \\
\cline { 2 - 6 } & & & & & \\
\hline & & & & & \\
Control & $7.6 \pm 0.39 \mathrm{~b}$ & $988.6 \pm 128.0 \mathrm{bc}$ & $282.6 \pm 31.60$ & $122.1 \pm 12.60 \mathrm{~b}$ & $49.9 \pm 3.96 \mathrm{a}$ \\
Co & $1072.2 \pm 46.70 \mathrm{a}$ & $584.2 \pm 21.2 \mathrm{c}$ & $169.9 \pm 3.28$ & $115.3 \pm 9.70 \mathrm{~b}$ & $31.7 \pm 1.88 \mathrm{~b}$ \\
SNP & $48.6 \pm 2.40 \mathrm{~b}$ & $1668.7 \pm 202.0 \mathrm{~b}$ & $243.1 \pm 13.70$ & $196.8 \pm 18.20 \mathrm{a}$ & $31.2 \pm 2.49 \mathrm{~b}$ \\
Co + SNP & $1078.0 \pm 143.00 \mathrm{a}$ & $2620.1 \pm 442.0 \mathrm{a}$ & $237.0 \pm 41.80$ & $185.9 \pm 29.70 \mathrm{a}$ & $35.0 \pm 5.07 \mathrm{~b}$ \\
$F$-Test & $* * *$ & $* *$ & $\mathrm{~ns}$ & $*$ & $*$ \\
\hline
\end{tabular}

Each value refers to the average of three replicates and shows the standard error (SE). Different letters int the same column indicate significant differences according to Duncan's multiple range test $(p<0.05)$.

\section{DISCUSSION}

Cobalt excessively absorbed by the roots, accumulates at the tips of the leaves, mainly following the transpiration stream and may indicate symptoms of toxicity depending on the species (Pandey and Sharma, 2002; Kabata-Pendias, 2011). Chlorosis in young leaves, which is closely linked with Fe chloroses, and later turns to necrotic spots on chlorotic areas are typical symptoms of Co toxicity.

In the study, decreases observed in biomass production (shoot and root FW and DW) (Figure 1) and photosynthetic pigment contents (Chl $a, \mathrm{Chl} b$, and Car) (Table 1) of the plants might be an indicator of Co-toxicity. The reduction in chlorophyll contents, a common symptom of toxicity of HMs (Jayakumar et al., 2007; Lwalaba et al., 2020), could be explained by reducing the availability of Fe for chlorophyll-heme biosynthesis (Pandey and Sharma, 2002). Also, the reduction in Fe concentration in shoots due to the toxic effects of Co could cause decreases in photosynthetic pigments (Figure 3A). This could be related to the role of $\mathrm{Fe}$ in the photosynthetic electron transport chain and photo-chlorophyll molecule (Rochaix, 2011). The findings related to the toxicity of excess Co applied to tomato (Gopal et al., 2003; Chatterjee and Chatterjee, 2005), to mung bean (Agnihotri et al., 2014), and to barley genotypes (Lwalaba et al., 2020) are consistent with the results.

In plants exposed to HM, generally, cellular components such as membranes, nucleic acids, chloroplast pigments are damaged due to the effects of the produced ROS and deteriorating enzymatic and non-enzymatic antioxidant balances (Gupta et al., 2013). In the study, Co stress causes an increase in membrane permeability, contents of $\mathrm{H}_{2} \mathrm{O}_{2}$ and MDA, and proline accumulation (Table 2). Acting as an excellent osmolyte, proline plays three vital roles during stress, as a metal chelator, an antioxidative defense molecule, and a signaling molecule (Hayat et al., 2012). Many works have been carried out to investigate the effects of excess Co on the induction of the non-enzymatic stress parameters (Ali et al., 2010; Karuppanapandian and Kim, 2013; Mostofa et al., 2014). On the other hand, enzymatic activities (CAT and APX) increased in Co-toxic plants (Figure 2). The possible reason for these increases might be avoiding oxidative damage. Published literature on the effects of excess Co on growth parameter, photosynthetic pigments and the activities of antioxidative enzymes in plants supports presented findings such as Gopal et al. (2003) and Chatterjee and Chatterjee (2005) in tomato, Ali et al. (2010) in chickpea, and Karuppanapandian and Kim (2013) in Indian mustard.

The results also showed that the application of SNP along with Co has positive effects on FWs in shoot and root and the contents of Chl $a$, Chl $a+b$, Car, compared to Co applied plants (Figure 1A, Table 1). These positive effects of SNP on biomass productions and chlorophyll contents could be related to (i) protection of plants by NO against oxidative membrane damage and its activations on root biomass (about 30\% in root FW) (Figure 1A), and (ii) inducing effects of SNP on NO generation (Panda et al., 2011). Also, the significant decrease observed in the contents of $\mathrm{H}_{2} \mathrm{O}_{2}$ and MDA and proline accumulation with the Co+SNP application could be explained by the positive effects of SNP on antioxidant enzymes (Table 2). Mostofa et al. (2014) reported that exogenous SNP $(200 \mu \mathrm{M})$ caused a significant decrease in the content of $\mathrm{H}_{2} \mathrm{O}_{2}$ and MDA and proline accumulation in $\mathrm{Cu}$ stressed plants. Reduced MDA, $\mathrm{H}_{2} \mathrm{O}_{2}$ content and proline accumulation by SNP has also been reported in tomato plants (Wang et al., 2010) and rice seedlings (Mostofa et al., 2014) under $\mathrm{Cu}$ stress, and in rice plants under Cd stress (Panda et al., 2011). 
Numerous studies have shown that heavy metals applied to the rooting media caused an increase in their concentrations in the roots and shoots of plants (Jayakumar et al., 2007; Ali et al., 2010; Agnihotri et al., 2014). Table 3 shows that applied Co caused an increase in the shoot and root Co concentration, Co uptake, and the TAR value of Co. Also, a majority of Co accumulated in roots, while a small amount was accumulated in shoots. The reason for Co accumulation in roots of the plant likely to be a precaution of the roots to harmful effects of excess Co by forming a storage site. Some organelles in the cell, like trichomes, could serve as HMs storage sites for detoxification or secrete various secondary metabolites to neutralize metal toxicity (Emamverdian et al., 2015). Another possible reason might be its immobilization in the vacuoles of the root's cells, inhibiting its toxicity by forming a protective barrier (Klink et al., 2013). As seen in Table 3, Co+SNP applications caused an increase in shoot Co concentration, whereas a reduction in the root Co concentration, compared to Co applied plants. Similar effects of Co+SNP on especially in FWs of shoot and root were found (Figure 1). The increase in shoot Co concentration with Co+SNP application could be related to the positive effects of NO on shoot development. Cui et al. (2010) reported that exogenous $\mathrm{NO}$ caused an increase in $\mathrm{H}^{+}$-ATPase enzyme activity that plays a vital role in the transport of multiple ions, in the shoot and root of tomato plants. This could be associated with the regulatory effects of NO in plant cells. In plants, NO signaling cascades are capable to transmit many environmental and hormonal stimuli either directly or indirectly (Rico-Lemus and Rodríguez-Garay, 2014). On the other hand, the decrease of Co concentration in root could be associated with inducing the defense mechanisms in root to prevent oxidative damage under stress conditions (Wang et al., 2010). Plants are capable of producing the NO molecule in its own roots to inhibit excess metallic ion mobilization to upper organs, thus they could avoid the toxicity effects of HMs (Xiong et al., 2009). The increases in TAR gained by the effects of both Co and Co+SNP applications can be associated with the higher Co level in the growth medium. Cikili et al. (2016) reported that the TAR of Cd showed an increase depending on the $\mathrm{Cd}$ dosage in the Solanaceae family. Sharma and Agrawal (2006) have associated the high TAR of $\mathrm{Cd}$ and $\mathrm{Zn}$ in the carrot plant with the existence of high $\mathrm{Cd}$ and $\mathrm{Zn}$ in growth media.

Plants need metallic cations for redox activity in enzymatic and photosynthetic reactions. These cations were studied in two groups as redox-active ( $\mathrm{Fe}, \mathrm{Cu}, \mathrm{Cr}$, and $\mathrm{Co}$ ) and redox-inactive ( $\mathrm{Zn}, \mathrm{Ni}, \mathrm{Cd}$, and $\mathrm{Al}$ ) (Singh et al., 2015). In the study, although the Fe concentration in the shoot and root tended to decrease with excess Co due to competition between Co and Fe ions, applied SNP caused a notable increase in Fe concentration in the shoot (Figure 3A). The decreasing trend in Fe concentration with excess Co might be related to using the same physiological binding site these two cations (Mengel et al., 2001) and thus excess Co could cause a decrease in the uptake and mode of action of other heavy metals, including $\mathrm{Fe}$ (Gopal et al., 2003). In addition, the possible cause of the increase in shoot and root Fe concentration by the effects of SNP (Figure 3A) may be the interaction between NO and Fe in heme or Fe-S groups due to forming nitrosyl complexes in target molecules (Ramirez et al., 2011). Increases or decreases in metallic cation concentrations with the effect of excess Co could be associated with the antagonistic or synergistic interaction between Co and these cations (Figure 3). Cobalt behaves like $\mathrm{Fe}, \mathrm{Mn}, \mathrm{Zn}$, and $\mathrm{Cu}$ during root absorption and transported in a similar way in the forms of binding to complexing organic compounds, as a chelate (Mengel et al., 2001). The adverse effects of excess Co on biological activity in the rhizosphere might also inhibit the absorption of other metallic cations (Zaborowska et al., 2016). The observed decreases in the concentration of $\mathrm{Fe}, \mathrm{Cu}, \mathrm{Mn}$, and $\mathrm{Zn}$ caused by toxic Co levels are in accordance with the findings reported by Jayakumar et al. (2007) in the radish plant. On the other hand, NO molecules can react with transition metals of metalloproteins to form metal-nitrosyl complexes and this molecule could bind to $\mathrm{Fe}, \mathrm{Zn}$, or $\mathrm{Cu}$ centers of metalloproteins through coordination bonding (Ford, 2010).

The net accumulation via roots indicates the amount of Co deposited by a unit root in the upper organs of a plant (Moradi and Ehsanzadeh, 2015). Positive or negative effects of applications on the net accumulation via roots are either due to the negative effect of the Co levels on the roots or due to the positive effect of SNP on the shoots and roots. The increases in the net accumulation of Co could be a dose-dependent effect (Table 4). The decreases in the net accumulation of $\mathrm{Cu}$ might be associated with the antagonistic effects of $\mathrm{Co}$ ions on $\mathrm{Cu}$ ions that have been in the same redox-active group (Singh et al., 2015). Ameliorative effects of SNP on the biomass production and photosynthetic pigments (Figure 1, Table 1) could also affect positively the net accumulation of Fe and Mn. Similar results were reported by Moradi and Ehsanzadeh (2015) for Cd ions in safflower. 


\section{CONCLUSIONS}

It seemed that excess Co caused toxic effects on growth and photosynthetic pigments in iceberg lettuce that have resulted in a reduction of biomass production and photosynthetic pigments. The inhibition of photosynthesis could be related to the effect of $\mathrm{Co}$ on $\mathrm{Fe}$ concentration in plant and/or translocation of Fe from root to upper organs. Excess Co also caused an increase in components occurring in toxicity stress, such as membrane permeability, the content of $\mathrm{H}_{2} \mathrm{O}_{2}$ and malondialdehyde (MDA), and proline accumulation and led to the increase in enzymatic activities (catalase and ascorbate peroxidase) in leaves. On the other hand, applied sodium nitroprusside (SNP) together with Co partially decelerated the toxic effects of $\mathrm{Co}$ in iceberg lettuce. The reduction in the contents of $\mathrm{H}_{2} \mathrm{O}_{2}$ and MDA and proline accumulation, and also increase in the concentration of $\mathrm{Fe}$ in shoot and root could be a piece of evidence for these results. All these data indicated the importance of exogenous nitric oxide (NO) in plant growth, micronutrient uptake, and its accumulation and in the protection against deleterious effects of $\mathrm{Co}$. The protective effect of exogenous $\mathrm{NO}$ on Co toxicity in lettuce plant could depend on NO-induced increase in antioxidant enzyme activity. Also, the reactive oxygen species (ROS) binding capacity of $\mathrm{NO}$ and its multifunctional roles in plant cellular mechanisms could help cells to cope with stress conditions.

All these data indicated the importance of exogenous SNP in growth, uptake, and accumulation of micronutrients and in the protection against deleterious effects of Co. The protective effect of exogenous NO on lettuce plants could depend on the regulation of ion imbalance and NO-induced increase in antioxidant enzyme activity. Studies on the toxic effects of metallic ions on leafy (edible) vegetables are still insufficient. The effects of metallic cations, especially heavy metals, on such vegetables which have high consumption, need more investigation.

\section{REFERENCES}

Agnihotri, R.R., Vamil, R., Singh, G., Ahmad, M., and Sharma, R. 2014. Effect of molybdenum and cobalt induced heavy metal stress on seedling growth stage of Vigna radiata. Acta Botanica Hungarica 56(1-2):227-241. doi:10.1556/ABot.56.2014.1-2.15.

Ali, B., Hayat, S., Hayat, Q., and Ahmad, A. 2010. Cobalt stress affects nitrogen metabolism, photosynthesis and antioxidant system in chickpea (Cicer arietinum L.) Journal of Plant Interactions 5(3):223-231. doi:10.1080/17429140903370584.

Bai, X.Y., Dong, Y.J., Xu, L.L., Kong, J., and Liu, S. 2015. Effects of exogenous nitric oxide on physiological characteristics of perennial ryegrass under cadmium and copper stress. Russian Journal of Plant Physiology 62(2):237245. doi:10.1134/S1021443715020028.

Bates, L.S., Waldren, R.P., and Teare, I.D. 1973. Rapid determination of free proline for water-stress studies. Plant and Soil 39:205-207. doi:10.1007/BF00018060.

Chance, B., and Maehly, A.C. 1955. Assay of catalases and peroxidases. Methods in Enzymology 2:764-775. doi:10.1016/S0076-6879(55)02300-8.

Chatterjee, J., and Chatterjee, C. 2005. Deterioration of fruit quality of tomato by excess cobalt and its amelioration. Communication in Soil Science and Plant Analysis 36(13-14):1931-1945. doi:10.1081/CSS-200062518.

Cikili, Y., Samet, H., and Dursun, S. 2016. Cadmium toxicity and its effects on growth and metal nutrient ion accumulation in Solanaceae plants. Journal of Agricultural Science 22:576-587.

Cui, X.M., Zhang, Y.K., Wu, X.B., and Liu, C.S. 2010. The investigation of the alleviated effect of copper toxicity by exogenous nitric oxide in tomato plants. Plant, Soil and Environment 56(6):274-281.

Emamverdian, A., Ding, Y., Mokhberdoran, F., and Xie, Y. 2015. Heavy metal stress and some mechanisms of plant defense response. The Scientific World Journal 215:756120.

Ford, P.C. 2010. Reactions of NO and nitrite with heme models and proteins. Inorganic Chemistry 49(14):6226-6239. doi:10.1021/ic902073z.

Gopal, R., Dube, B.K., Sinha, P., and Chatterjee, C. 2003. Cobalt toxicity effects on growth and metabolism of tomato. Communications in Soil Science and Plant Analysis 34(5-6):619-628. doi:10.1081/CSS-120018963.

Gupta, D.K., Corpas, F.J., and Palma, J.M. (eds.) 2013. Heavy metal stress in plants. Springer-Verlag, Berlin, Heidelberg, Germany. doi:10.1007/978-3-642-38469-1.

Hayat, S., Hayat, Q., Alyemeni, M.N., Wani, A.S., Pichtel, J., and Ahmad, A. 2012. Role of proline under changing environments: a review. Plant Signaling and Behaviour 7(11):1456-1466. doi:10.4161/psb.21949.

Hodges, D.M., De Long, J.M., Forney, C.F., and Prange, R.K. 1999. Improving the thiobarbituric acid-reactive-substances assay for estimating lipid peroxidation in plant tissues containing anthocyanin and other interfering compounds. Planta 207:604611. doi:10.1007/s004250050524.

Jayakumar, K., Jaleel, C.A., and Vijayarengan, P. 2007. Changes in growth, biochemical constituents, and antioxidant potentials in radish (Raphanus sativus L.) under cobalt stress. Turkish Journal of Biology 31(3):127-136. 
Kabata-Pendias, A. 2011. Trace elements in soils and plants. $4^{\text {th }}$ ed. p. 227-235. CRC Press/Taylor and Francis Group, Boca Raton, Florida, USA.

Karuppanapandian, T., and Kim, W. 2013. Cobalt-induced oxidative stress causes growth inhibition associated with enhanced lipid peroxidation and activates antioxidant responses in Indian mustard (Brassica juncea L.) leaves. Acta Physiologiae Plantarum 35(8):2429-2443. doi:10.1007/s11738-013-1277-y.

Klink, A., Maciol, A., Wislocka, M., and Krawczyk, J. 2013. Metal accumulation and distribution in the organs of Typha latifolia L. (cattail) and their potential use in bioindication. Limnologica-Ecology and Management of Inland Waters 43(3):164-168. doi:10.1016/j.limno.2012.08.012.

Li, H.F., Gray, C., Mico, C., Zhao, F.J., and McGrath, S.P. 2009. Phytotoxicity and bioavailability of cobalt to plants in a range of soils. Chemosphere 75(7):979-986. doi:10.1016/j.chemosphere.2008.12.068.

Lichtenthaler, H.K. 1987. Chlorophylls and carotenoids: pigments of photosynthetic biomembranes. Methods in Enzymology 148:350-382. doi:10.1016/0076-6879(87)48036-1.

Lwalaba, J.L.W., Louis, L.T., Zvobgo, G., Richmond, M.E.A., Fu, L., Naz, S., et al. 2020. Physiological and molecular mechanisms of cobalt and copper interaction in causing phytotoxicity to two barley genotypes differing in Co tolerance. Ecotoxicology and Environmental Safety 187:109866. doi:10.1016/j.ecoenv.2019.109866.

Marschner, H. 2012. Marschner's mineral nutrition of higher plants. $3^{\text {rd }}$ ed. Elsevier, London, UK.

Mengel, K., Kirkby, E.A., Kosegarten, H., and Appel, T. 2001. Principles of plant nutrition. $5^{\text {th }}$ ed. p. 649-654. Kluwer Academic Publishers, Dordrecht, The Netherlands.

Miller, R.O. 1998. High-temperature oxidation: dry ashing. p. 66-69. In Kalra, P.Y. (ed.) Handbook of reference methods for plant analysis. Taylor and Francis/CRC Press, Boca Raton, Florida, USA.

Moradi, L., and Ehsanzadeh, P. 2015. Effects of Cd on photosynthesis and growth of safflower (Carthamus tinctorius L.) genotypes. Photosynthetica 53(4):506-518. doi:10.1007/s11099-015-0150-1.

Mostofa, M.G., Seraj, Z.I., and Fujita, M. 2014. Exogenous sodium nitroprusside and glutathione alleviate copper toxicity by reducing copper uptake and oxidative damage in rice (Oryza sativa L.) seedlings. Protoplasma 251(6):1373-1386. doi:10.1007/s00709-014-0639-7.

Mukherjee, S.P., and Choudhuri, M.A. 1983. Implications of water stress-induced changes in the levels of endogenous ascorbic acid and hydrogen peroxide in Vigna seedlings. Physiologia Plantarum 58(2):166-170. doi:10.1111/j.1399-3054.1983.tb04162.x.

Nakano, Y., and Asada, K. 1981. Hydrogen peroxide is scavenged by ascorbate-specific peroxidase in spinach chloroplasts. Plant and Cell Physiology 22:867-880. doi:10.1093/oxfordjournals.pcp.a076232.

Panda, P., Nath, S., Chanu, T.T., Sharma, G.D., and Panda, S.K. 2011. Cadmium stress-induced oxidative stress and role of nitric oxide in rice (Oryza sativa L.) Acta Physiologiae Plantarum 33(5):1737-1747. doi:10.1007/s11738-011-0710-3.

Pandey, N., and Sharma, C.P. 2002. Effect of heavy metals $\mathrm{Co}^{2+}, \mathrm{Ni}^{2+}$ and $\mathrm{Cd}^{2+}$ on growth and metabolism of cabbage. Plant Science 163(4):753-758. doi:10.1016/S0168-9452(02)00210-8.

Ramirez, L., Simontacchi, M., Murgia, I., Zabaleta, E., and Lamattina, L. 2011. Nitric oxide, nitrosyl iron complexes, ferritin and frataxin: a well equipped team to preserve plant iron homeostasis. Plant Science 181(5):582-592. doi:10.1016/j.plantsci.2011.04.006.

Rico-Lemus, M., and Rodríguez-Garay, B. 2014. SNP as an effective donor of nitric oxide for in vitro. Journal of Plant Biochemistry and Physiology 2(3):1000e127. doi:10.4172/2329-9029.1000e127.

Rochaix, J.D. 2011. Regulation of photosynthetic electron transport. Biochimica et Biophysica Acta (BBA) 1807(8):878-886. doi:10.1016/j.bbabio.2010.11.010.

Sharma, R.K., and Agrawal, M. 2006. Single and combined effects of cadmium and zinc on carrots: uptake and bioaccumulation . Journal of Plant Nutrition 29(10):1791-1804. doi:10.1080/01904160600899246.

Shigeoka, S., Ishikawa, T., Tamoi, M., Miyagawa, Y., Takeda, T., Yabuta, et al. 2002. Regulation and function of ascorbate peroxidase isoenzymes. Journal of Experimental Botany 53(372):1305-1319. doi:10.1093/jexbot/53.372.1305.

Singh, S., Tripathi, D.K., Chauhan, D.K., and Dubey, N.K. 2015. Glutathione and phytochelatins mediated redox homeostasis and stress signal transduction in plants: an integrated overview. p. 285-310. In Ahmad, P. (ed.) Plant metal interaction: Emerging remediation techniques. Elsevier, Amsterdam, The Netherlands.

Wang, S.H., Zhang, H., Jiang, S., Zhang, J.L., He, Q.Y., and He, H.Q. 2010. Effects of the nitric oxide donor sodium nitroprusside on antioxidant enzymes in wheat seedling roots under nickel stress. Russian Journal of Plant Physiology 57(6):833-839. doi:10.1134/S1021443710060129.

Xiong, J., An, L., Lu, H., and Zhu, C. 2009. Exogenous nitric oxide enhances cadmium tolerance of rice by increasing pectin and hemicellulose contents in root cell wall. Planta 230(4):755-765. doi:10.1007/s00425-009-0984-5.

Yan, B., Dai, Q., Liu, X., Huang, S., and Wang, Z. 1996. Flooding-induced membrane damage, lipid oxidation and activated oxygen generation in corn leaves. Plant and Soil 179:261-268. doi:10.1007/BF00009336.

Zaborowska, M., Kucharski, J., and Wyszkowska, J. 2016. Biological activity of soil contaminated with cobalt, tin, and molybdenum. Environmental Monitoring and Assessment 188(7):398-408. doi:10.1007/s10661-016-5399-8. 